\section{Transplantation of Wharton's Jelly Mesenchymal Stem Cells to Improve Cardiac Function in Myocardial Infarction Rats}

\section{Abstract}

Background: Myocardial infarction (MI) is a fatal disease that is increasing in incidence. The worst sequelae of $\mathrm{Ml}$ include myocardial fibrosis and deterioration of pumping function that can lead to irreversible heart failure. This study aims to compare the therapeutic effect of undifferentiated versus TGF- $\beta 2-$ stimulated Wharton's jelly mesenchymal stem cells (WJ-MSCs) in MI rats.

Results: Left anterior descending (LAD) artery ligation-induced myocardial infarct rats were used to evaluate changes in left ventricular function and fibrosis following injection of PBS or $1.6 \times 10^{6}$ undifferentiated or TGF- $\beta 2$-stimulated WJ-MSCs into the infarct border zone of myocardium. Electrocardiograph, echocardiogram, serum cardiac Troponin I level, Masson's Trichrome staining, immunohistochemistry were used to analyze the therapeutic effects. We found that transplantation of both undifferentiated and TGF- $\beta 2$ stimulated WJ-MSCs decreased serum Cardiac Troponin I levels, improved fractional shortening, ameliorated ejection fraction changes, and decreased the area of myocardial fibrosis. Moreover, some of the transplanted human WJ-MSCs survived in the myocardium.

Conclusions: Transplantation of either undifferentiated or TGF- $\beta 2$ stimulated WJ-MSCs improved left ventricular function after $\mathrm{MI}$ and increased survival. The effects were most marked using undifferentiated WJ-MSCs. These results indicate WJ-MSCs as a potential stem cell source for use in myocardial infarct therapy.

Keywords: Wharton's jelly mesenchymal stem cells; Myocardial infarction; Transforming growth factor- $\beta 2$; Transplantation

Received: November 06, 2015; Accepted: December 18, 2015; Published: December 28,2015

\section{Background}

Myocardial infarction is an ischemic heart condition caused by occlusion of a coronary artery. The occlusion most commonly occurs in the left anterior descending branch of the coronary artery. Injury of myocardiocytes and subsequent heart failure can occur 20-30 minutes after the onset of cardiac ischemia [13]. Once acute myocardial infarction (AMI) occurs, myocardial atrophy, degeneration, fibrosis and other pathologies may develop [4]. Healthy myocardiocytes must then increase their contractile force to compensate for dead cells to maintain normal pumping. This compensation leads to a vicious cycle whereby compensatory mechanisms proceed to accelerate cardiac hypertrophy [5].
Chen-Yuan Hsiao ${ }^{1,2,3}$, Pei-Jiun Tsai ${ }^{3,4}$,

Pei-Chun Chu ${ }^{3}$, Shin-I Liü ${ }^{3}$, Chia-Hsin Pan ${ }^{3}$, Chie-Pein Chen ${ }^{5}$,Cheng-Hsi Su ${ }^{6}$,Zen-Chung Weng ${ }^{7,8}$,Tien-Hua Chen ${ }^{3,9}$,Jia-Fwu Shyu ${ }^{10}$, Hsiao-Huang Chang ${ }^{11,12}$, and Hwai-Shi Wang ${ }^{3}$

1 Graduate Institute of Medical Sciences, National Defense Medical Center, Taipei, Taiwan, R.O.C.

2 Department of Surgery, National Yang Ming University Hospital, Yilan, Taiwan, R.O.C.

3 Institute of Anatomy and Cell Biology, School of Medicine, National Yang Ming University, Taipei, Taiwan, R.O.C.

4 Department of Critical Care Medicine, Veterans General Hospital, Taipei, Taiwan, R.O.C.

5 Division of High Risk Pregnancy, Mackay Memorial Hospital, Taipei, Taiwan, R.O.C.

6 Department of Surgery, Cheng Hsin General Hospital, Taipei, Taiwan, R.O.C.

7 Cardiovascular Surgery, Wei-Gong Memorial Hospital, Miaoli, Taiwan, R.O.C.

8 Division of Cardiovascular Surgery, Cardiovascular Center, Taipei Medical University and Taipei Medical University Hospital, Taipei, Taiwan, R.O. C.

9 Department of Surgery, Veterans General Hospital, Taipei, Taiwan, R.O.C.

10 Department of Biology and Anatomy, National Defense Medical Center, Taipei, Taiwan, R.O.C.

11 Division of Cardiovascular Surgery, Department of Surgery, Veterans General Hospital, Taipei, Taiwan, R.O.C

12 School of Medicine, College of Medicine, Taipei Medical University, Taipei, Taiwan, R.O.C.

Corresponding author: Hwai-Shi Wang Hsiao-Huang Chang Jia-Fwu Shyu

” hswang@ym.edu.tw shchang@vghtpe.gov.tw shyujeff@ndmctsgh.edu.tw

Institute of Anatomy and Cell Biology, School of Medicine, National Yang Ming University, 201 Shih-Pai Road Section 2, Taipei, Taiwan 112, R.O.C Hsiao-Huang Chang, Division of Cardiovascular Surgery, Department of Surgery, Veterans General Hospital, Taipei, 201 Shih-Pai Road Section 2, Taipei, Taiwan 112, R.O.C

Department of Biology and Anatomy, National Defense Medical Center,161 Ming Chuan E. Road Section 6, Taipei, Taiwan 114, R.O.C

$\begin{aligned} \text { Tel: } & +(886)-2-28267035,+(886)-2-28718681 \\ & +(886)-2-87922484\end{aligned}$

Citation: Hsiao CY, Tsai PJ,Chu PC Transplantation of Wharton's Jelly Mesenchymal Cells to Improve Cardiac Function in Myocardial Infarction Rats. J Biomedical Sci. 2016, 5:1. 
Management of a patient with AMI is a medical emergency. The current standard treatment of acute myocardial infarction is reperfusion therapy such as percutaneous coronary intervention (PCI) or thrombolytic drugs. Either treatment can rescue the infarction symptom but cannot reverse the ischemia or apoptotic myocardiocytes. Compared with fibrinolysis, $\mathrm{PCl}$ results in less reocclusion, improved left ventricular function and improved overall outcome (including reduced risk of stroke). Thus, $\mathrm{PCl}$ is the preferred treatment. However, this treatment requires sophisticated cardiologists with advanced equipment. Some patients may need a coronary artery bypass graft (CABG) due to $\mathrm{PCl}$ failure, coronary occlusion not amenable to $\mathrm{PCl}$, the presence of refractory symptoms after $\mathrm{PCl}$, cardiogenic shock, or mechanical complications such as ventricular rupture, acute mitral regurgitation, ventricular septal defect, or multivessel disease. Unfortunately, CABG is a highly risky surgical procedure under such circumstances and may cause many severe sequelae. Stem cell transplantation may be another therapeutic choice.

Mesenchymal stems cells (MSCs) are multipotent stem cells that were first isolated from bone marrow [6]. MSCs express specific surface markers such as CD73, CD90, and CD105, while hematopoietic cell antigens such as CD45 and CD34 are absent [7]. MSCs can differentiate into cells of the 3 germ layers [8,9], including smooth muscle cells and endothelial cells of blood vessels, nerve cells, adipocytes, chondrocytes, hepatocytes, and cardiomyocytes [8-10]. In addition to bone marrow, Wharton's Jelly MSCs (WJ-MSCs) are another sources of MSCs [11]. Under appropriate culture conditions, WJ-MSCs can differentiate into cardiomyocytes, adipocytes, chondrocytes, and osteocytes $[11,12]$. WJ-MSCs can also differentiate into nerve cells, liver cells [13], and germ cells [14]. WJ-MSCs lack type II human leukocyte antigen (HLA-2), HLA-DR, -DP, and -DQ which reduces the immune response and immune suppression effects [15]. Since WJ-MSCs possess immunomodulatory and immunosuppressive capabilities [16], they can inhibit the immune response caused by T lymphocytes in allogenic transplantation $[17,18]$.

Stem cells from many different sources have been used to repair myocardial injury in animal experiments, including human bone marrow mesenchymal stem cells [19], human endothelial progenitor cells [20], and human bone-marrow-derived very small embryonic-like stem cells [21]. In addition, Min and colleagues reported that the use of embryonic stem cells in regenerative therapy after myocardial infarction is highly feasible in mice. The implantation of embryonic stem cells into sites of myocardial infarction induces their differentiation into cardiomyocytes that partially restore cardiac function [22]. While such research gives a positive outlook on the therapeutic potential of stem cell therapy after AMI in animals, whether therapeutic stem cells should be differentiated before implantation is not clear.

Current research suggests that 3 types of transforming growth factor- $\beta$ (TGF- $\beta$ ) play distinct regulatory effects during cell growth and differentiation [23]. TGF- $\beta 1$ induces embryonic stem cells to differentiate into smooth muscle cells [24]. TGF- $\beta 3$ promotes chondrogenic differentiation in human MSCs, and TGF- $\beta 3$ knockout mice suffer from cleft palate [25]. TGF- $\beta 2$ knockout mice have defects in the lungs and urinary system $[26,27]$.
TGF- 32 knockout mice also have cardiovascular anomalies such as failure of normal looping, endocardial cushion differentiation, and ventricular remodeling $[23,28,29]$. In addition, treatment with TGF- $\beta 2$ significantly increases the differentiation of beating cardiomyocytes from mouse embryonic body cells [30,31]. In general, TGF- $\beta 2$ but not TGF- $\beta 1$ or TGF- $\beta 3$ plays a crucial role in the differentiation of the mesoderm, exerting particular influence on the growth and development of the cardiovascular system.

In this study, we compare the therapeutic effects of undifferentiated and differentiated mesenchymal stem cells. We also study the process whereby MSCs repair myocardial infarction in rats. The results of this study should provide basic and necessary information to allow future use of cell regenerative therapy in myocardial infarct patients.

\section{Methods}

\section{Cell Culture}

Institutional Review Board approval was obtained for all procedures. With the written informed consent of parents, fresh human umbilical cords were obtained after birth and stored in Hank's balanced salt solution (Biological Industries, Israel) for no more than 24 hours before tissue processing to obtain MSCs. MSCs were isolated from umbilical cord Wharton's jelly as previously described [11]. The blood vessels were removed, followed by scraping the mesenchymal tissue from the Wharton's jelly with a scalpel. The mesenchymal tissue was centrifuged at $250 \times \mathrm{g}$ for 5 minutes at room temperature. The pellet was washed with serum-free Dulbecco's modified Eagle's medium (DMEM) (Gibco, Grand Island, NY), resuspended in $10 \mathrm{~mL}$ of DMEM and centrifuged at $250 \times \mathrm{g}$ for 5 minutes at room temperature. The pellet was resuspended in $15 \mathrm{~mL}$ of DMEM containing $0.2 \mathrm{~g} / \mathrm{mL}$ of collagenase and incubated for 16 hours at $37^{\circ} \mathrm{C}$. Cells were washed, resuspended in $10 \mathrm{~mL}$ of DMEM containing $2.5 \%$ trypsin, incubated for 30 minutes at $37^{\circ} \mathrm{C}$. The cells were then washed and cultured in DMEM with $10 \%$ fetal bovine serum (FBS; Sigma, St. Louis, MO) and glucose $(4.5 \mathrm{~g} / \mathrm{L})$ in $5 \% \mathrm{CO} 2$ in a $37^{\circ} \mathrm{C}$ incubator. At the fourth to sixth passage, the WJ-MSCs were induced to differentiate into cardiomyocyte cells by culturing for 7 days in $4 \mathrm{ng} / \mathrm{mL}$ TGF- $\beta$ medium with $10 \%$ FBS (Sigma, St. Louis, MO) and $1 \%$ penicillin/streptomycin/amphotericin B (Biological Industries, Kibbutz Beit Haemek, Israel).

\section{Myocardial Infarction (MI) Model}

All experiments were performed in accordance with the animal use guidelines of Yang Ming University, and the experimental protocol was approved by the Yang Ming University research animal resources committee. Eight-week-old Sprague-Dawley rats (laboratory animal center, Yang Ming University, Taiwan) weighing 300-400 g were randomly placed into 4 groups: 1) Sham group, underwent sham surgery involving left thoracotomy without left anterior descending artery (LAD) ligation; 2) Control group, underwent LAD ligation and received normal saline (NS) injections; 3) MSC group, underwent LAD ligation and received injections of undifferentiated human WJ-MSCs; 4) TGF- $\beta 2$ group, underwent LAD ligation and received injection of TGF- $\beta 2-$ stimulated human WJ-MSCs. There were 8 rats in each group. 
The animals were not fed for at least 4 hours before surgery and were anesthetized with $40 \mathrm{mg} / \mathrm{mL}$ sodium pentobarbital (40 mg/ $\mathrm{kg}$, peritoneal injection). The anterior chest areas were shaved before surgery. The rats were then intubated and ventilated with a mechanical ventilator to enable oxygen as well as $2 \%$ isofluothane flow to lungs. Electrocardiography (ECG) electrodes were applied, and continuous ECG was recorded.

After disinfection with beta-iodine, a 2-cm transverse intercostal incision was made over the left anterior chest wall where heartbeats are felt most strongly. The thoracic cavity was entered, and the heart was explored. A wound retractor was used to extend the wound. Saline gauze was placed between the heart and lungs to push the lungs aside to avoid lung injury during the operation. The pericardium was opened, and the LAD was identified. Prolene (8-0) was used to ligate the LAD by tying 8 knots $2 \mathrm{~mm}$ below the tip of the left auricle. ECG was checked 15 minutes after ligation, and ST elevation was thought to indicate a successful model MI. Normal saline, undifferentiated human WJMSCs $(1.6 \times 106)$ or TGF- $\beta 2-$ stimulated human WJ-MSCs (1.6 $\times$ 106) were injected directly into the myocardium around the site of ligation 15 minutes after LAD ligation in rats in the control, MSC, and TGF- $\beta 2$ groups. Five equal injections for a total volume of $0.2 \mathrm{~mL}$ were given. The wound was then closed with 3-0 Vicryl and 4-O Nylon in layers. All the rats were placed under a warming lamp postoperatively and returned to cages after recovery of consciousness.

\section{Serum Biochemical Testing}

Blood samples were collected from the tail vein before LAD ligation and 6 hours, 2 days, 1 week, 2 weeks, 4 weeks, and 15 weeks after LAD ligation. The blood samples were centrifuged for 10 minutes at room temperature, and the serum was obtained to analyze cardiac troponin-I (C-TnI) levels by enzyme-linked immunosorbent assay (ELISA).

\section{Measurements of Cardiac Function - Echocardiog- raphy}

Echocardiography assessments were obtained before LAD ligation and 2 days, 2 weeks, 4 weeks, and 15 weeks after LAD ligation. The rats were anaesthetized with ketamine hydrochloride $(100 \mathrm{mg} /$ $\mathrm{kg}$, intramuscular injection), placed in the supine position, and the chest area shaved. Ultrasound transmission gel was spread evenly over the left chest. A 2-D/M mode echocardiogram was obtained using a Philips iU22 ultrasound operating system with a compact linear array probe L15-7io (7-15 mhz) to measure the left ventricular end diastolic diameter (LVEDD) and left ventricular end systolic diameter (LVESD). Echocardiography was performed 5 times for each examination. LVEDD and LVESD values were recorded and used to calculate the mean.

Left ventricular (LV) fractional shortening (FS) indicates the percent change in LV cavity dimensions at the base with systolic contraction, which is limited by significant apical wall motion abnormalities. The FS is calculated as [(LVEDD - LVESD) / LVEDD] $\times 100 \%$. The Simpson method allows determination of the left ventricle volume. The $\mathrm{LV}$ ejection fraction (EF) was calculated as [(LVEDD3 - LVESD3) / LVEDD3 ] × 100\%.

\section{Measurements of Cardiac Function: ECG Monitoring}

ECG assessments were obtained during the LAD ligation and 2 weeks, 4 weeks, and 15 weeks after LAD ligation. Rats were anaesthetized with ketamine hydrochloride $(100 \mathrm{mg} / \mathrm{kg}$, intramuscular injection), placed in the supine position, and ECG electrodes were applied subcutaneously.

\section{Perfusion and tissue embedding}

Rats were anaesthetized with $40 \mathrm{mg} / \mathrm{mL}$ sodium pentobarbital (40 mg/kg, intraperitoneal injection). The abdominal cavity was opened $1 \mathrm{~cm}$ below the xiphoid process of the sternum. The thoracic cavity was opened by cutting the diaphragm and cutting the ribs along the lateral surface up towards the second rib. The adhesion between the heart and sternum was separated. The pericardium was opened, and an $18 \mathrm{G}$ intravenous retention needle connected to a peristaltic pump was inserted into the left ventricle. The right auricle was cut to allow blood drainage. The rat was perfused with $400 \mathrm{~mL} 1 \mathrm{X}$ phosphate buffered saline (PBS) and then fixed in 4\% paraformaldehyde (Ferak, Berlin, Germany). The heart was then transected into several sections every 3-5 $\mathrm{mm}$ and placed sequentially in 30\% sucrose, $1: 130 \%$ sucrose plus Optimal Cutting Temperature compound (OCT) (Sakura Finetek USA Inc, Torrance, CA), and OCT for 16-18 hours at $4^{\circ} \mathrm{C}$ to dehydrate the sections. A small amount of OCT was added to cover the bottom of an appropriately-sized aluminum foil container. Excess OCT was removed, and the heart tissue was placed in the container and submerged in OCT. The container was flash-frozen in liquid nitrogen until the OCT solidified.

\section{Frozen tissue cryostat sections}

The temperature of the cryomicrotome was adjusted to $-30^{\circ} \mathrm{C}$ and the chamber temperature set to $-25^{\circ} \mathrm{C}$. The heart tissue was placed onto the loading platform and then cut into $0.5 \mu \mathrm{m}$ sections. The slices were affixed to slides and stored at $-20^{\circ} \mathrm{C}$.

\section{Masson's Trichome staining}

Tissue sections were placed at room temperature to thaw for 15 minutes. Tissue sections were washed with $1 \times$ Tris-buffered saline (TBS) for 5 minutes 3 times and treated with Bouin's fixative (Sigma, St. Louis, MO) at $56^{\circ} \mathrm{C}$ for 15 minutes. After cooling at room temperature, tissue sections were rinsed with tap water until excess Bouin's fixative was removed. Tissue sections were then stained with hematoxylin (Merck) for 7 minutes, rinsed with tap water for 5 minutes, followed by a final rinse with doubledistilled water. Tissue sections were stained with Biebrich scarlet acid fuchsin (Sigma, St. Louis, MO) for 5 minutes then rinsed with double-distilled water. A 1:1 solution of phosphomolibdic acid (Sigma, St. Louis, MO) and phosphotungstic acid (Sigma, St. Louis, MO) was applied for 15 minutes. After blotting dry with wipes, aniline blue stain (Sigma, St. Louis, MO) was applied for 8 minutes. Tissue sections were rinsed with double-distilled water and fixed in $1 \%$ frozen acetic acid solution (Merck) to stabilize staining. After rinsing with double-distilled water, sections were sequentially placed in $70 \%$ to $95 \%$ alcohol for dehydration. The slides were then air-dried and viewed with a microscope using appropriate filters. 


\section{Immunohistochemistry}

After thawing at room temperature for 15 minutes, tissue sections were washed with $1 \times$ TBS for 5 minutes 3 times, treated with acetone (Merck) for 3 minutes, and then washed with $1 \times$ TBS for 5 minutes 3 times. Proteinase $\mathrm{K}$ in TE-CaCl2 $(20 \mu \mathrm{g} /$ $\mathrm{mL}$ ) (Protech) was applied for 5 minutes and washed with $1 \times$ TBS for 5 minutes 3 times. After treating with blocking buffer for 30 minutes at room temperature, the tissue sections were incubated in a solution of primary antibody (Mouse anti-human nuclei monoclonal antibody, 1:200 (Chemicon); Mouse antihuman c-Troponin I monoclonal antibody, 1: 200 (Hytest); Rabbit anti-human connexin 43 polyclonal antibody, 1:50 (Invitrogen) at $4^{\circ} \mathrm{C}$ for $16-18$ hours. After 45 -min washes with $1 \times$ TBS, tissue sections were incubated for 1 hour in the dark at room temperature with Dylight488-labeled antibody to rabbit IgG, 1: 200; Dylight549 antibody to mouse IgG, 1: 200). After 3 washes with $0.05 \%$ TritonX-100 in TBS for 5 minutes, $1 \mathrm{mg} / \mathrm{mL}$ Hoechst 33258 (Sigma, St. Louis, MO) was added for 5 minutes. The tissue sections were finally washed 3 times with $0.05 \%$ TritonX-100 (Sigma, St. Louis, MO) in TBS for 5 minutes and viewed with a fluorescence microscope using appropriate filters.

\section{Statistical Analysis}

Each series of experiments was performed in triplicate. The results obtained from a typical experiment are expressed as the mean \pm standard deviation (SD). Statistical analysis was carried out using the SPSS 14.0 software program (Statistics Package for Social Sciences, SPSS Inc. Chicago, Illinois, USA). All continuous data are presented as the mean \pm SD. Group comparisons were made by one-way ANOVA followed by Dunnett's test. Survival was assessed using Kaplan-Meier survival curves. $p \leq 0.05$ was considered statistically significant.

\section{Results}

\section{TGF- $\beta 2$ successfully stimulate WJ-MSCs differentia- tion into cardiomyocyte}

The immunofluorescence staining of the cardiogenic differentiation marker, such as c-Troponin-I and connexin-43 were found to highly expression in the TGF- $\beta 2$ stimulated WJ-MSCs, confirming that 6 days TGF- $\beta 2$ treatment induced cardiomyocyte differentiation (Figure 1).

\section{Normalization of ECG in MI rats after transplantation of human umbilical cord undifferentiated WJ-MSCs or TGF- $\beta 2$ stimulated WJ-MSCs}

When myocardial infarction occurs, ECG will show ST elevation followed by ST depression or T-wave inversion. The ECGs of the sham group exhibited a normal pattern, while that of controls showed significant ST depression that progressed to ventricular tachycardia 15 weeks after LAD ligation, indicating that the myocardial infarction did not improve with time. In the TGF- $\beta 2$ group, the ECG at 2 weeks after LAD ligation showed ST depression that gradually returned to normal by 15 weeks after LAD ligation. In the MSC group, the ECG 2 weeks after LAD ligation also showed ST depression and returned to a normal pattern by 4 weeks after LAD ligation. These results demonstrate the reparative function

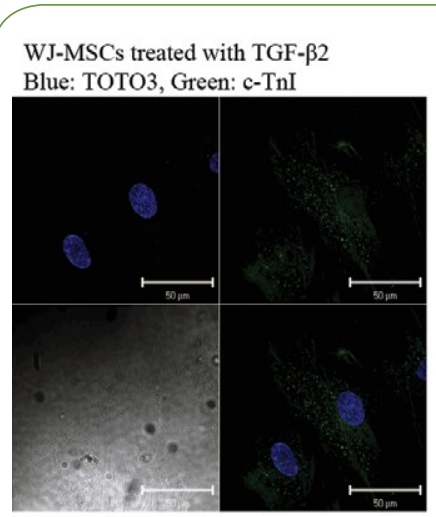

WJ-MSCs treated with TGF- $\beta 2$ Blue: TOTO3, Green: connexin-43

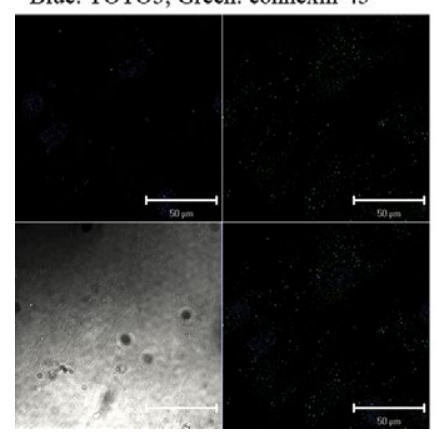

untreated WJ-MSCs Blue: TOTO3, Green: connexin-43

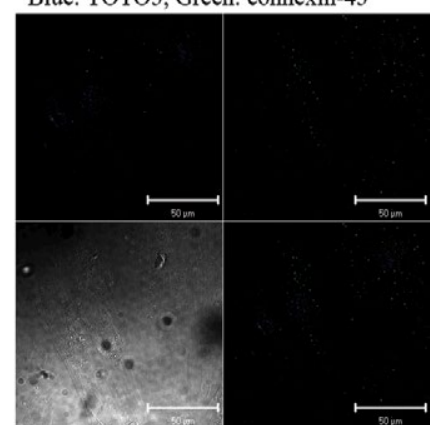

Figure 1 The immunofluorescence staining of the cardiogenic differentiation marker.

C-Troponin-I and connexin-43 were found to highly expression in the TGF- $\beta 2$ stimulated WJ-MSCs

of both undifferentiated WJ-MSCs and TGF- $\beta 2$ stimulated WJMSCs transplanted into damaged rat myocardium (Figure 2).

Transplantation of human umbilical cord undifferentiated WJ-MSCs or TGF- $\beta 2$-stimulated WJMSCs into $\mathrm{MI}$ rat myocardium rapidly reverses the increase in serum cardiac troponin I after LAD ligation

At the onset of myocardial infarction, the damaged myocardium releases specific enzymes into the bloodstream. Thus, serum testing for these specific cardiac enzymes is another indicator of acute myocardial infarction. Serum was collected from each group before surgery and 6 hours post surgery. There was no significant increase in cardiac troponin I (c-Tnl) in the sham group, but obvious increases were detected in rats 6 hours after receiving LAD ligation in the other 3 groups (Control, MSC, TGF- $\beta 2$ groups), indicating that all rats receiving $L A D$ ligation experienced acute myocardial infarction with severe myocardial damage. In addition, the serum c-Tnl level was significantly lower in both the MSC and TGF- $\beta 2$ groups than in controls. Thus, the transplanted MSCs appear to reverse cardiac damage after LAD ligation (Figure 3).

Transplantation of human umbilical cord undifferentiated WJ-MSCs or TGF-B2-stimulated WJMSCs into myocardium of MI rats improves cardiac function

Echocardiography in M-mode revealed gradual thinning of the left ventricular wall and decreased systolic function in the 


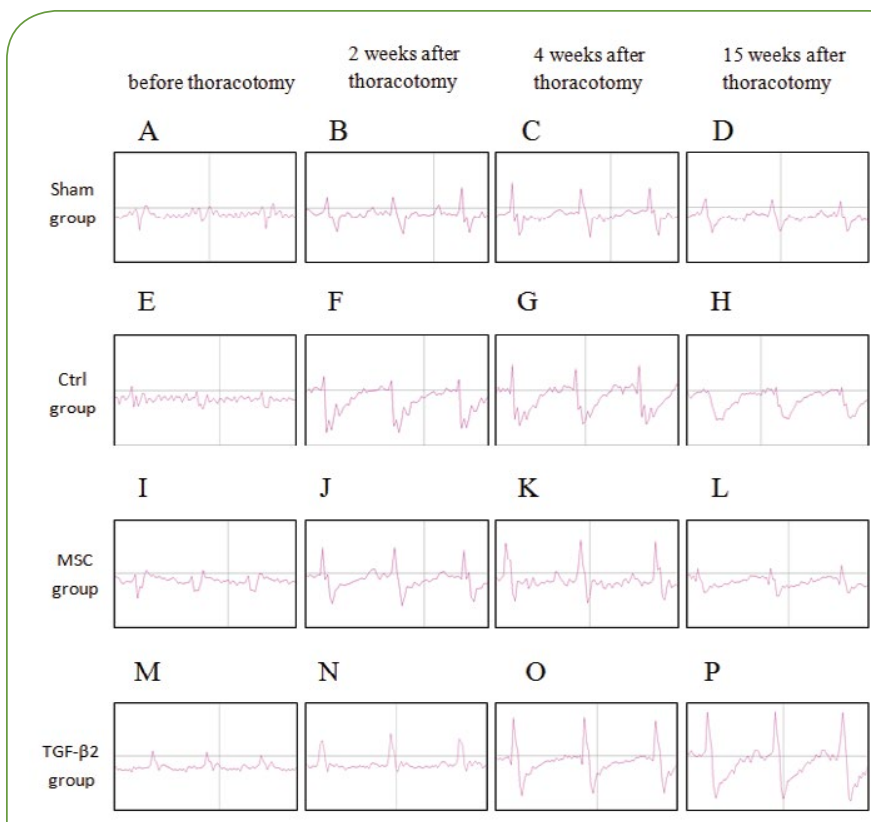

Figure 2 ECG changes.

While the ECG of control group progressed to ventricular tachycardia 15 weeks after LAD ligation, that of MSC group and TGF- $\beta 2$ group gradually returned to normal by 15 weeks after $L A D$ ligation.

A-D: ECG of rats in sham group. E-H: ECG of rats in Ctrl group. I-L: ECG of rats in MSC group. M-P: ECG of rats in TGF- $\beta 2$ group

A, E, I, M: before thoracotomy. B, F, J, N: 2 weeks after thoracotomy. C, G, K, O: 4 weeks after thoracotomy. D, H, L, P: 15 weeks after thoracotomy.

control group (Figure 4, E to $\mathrm{H}$ ). M-mode images from the MSC and TGF- $\beta 2$ groups also revealed thinning of the left ventricular walls at 2 weeks after LAD ligation (Figure 4, J and N). However, the degree of thinning and decrease in systolic function were less marked than the control group at 2 weeks, 4 weeks, and 15 weeks after LAD ligation. The improvements were better in the MSC group than in the TGF- $\beta 2$ group (Figure 4).

The LVESD and LVEDD both increased in rats that had undergone LAD ligation (Table 1). An increase in LVEDD indicates enlargement of the heart after myocardial infarction, and an increase in LVESD indicates disturbances in systolic function. Rats in the MSC and TGF- $\beta 2$ groups had smaller increases in LVESD and LVEDD than controls, indicating that cardiac enlargement and loss of systolic function due to MI were attenuated. This attenuation was greater in the MSC group than in the TGF- $\beta 2$ group.

Fractional shortening represents the rate of change in LVEDD and LVEDD and is used as an estimate of myocardial contractility. The ejection fraction is the fraction of blood pumped out of the left ventricle with each beat and is a useful measure of left ventricular performance. Because the FS and EF vary between rats, it is not meaningful to directly compare these parameters. Instead, we determined the percent of FS and EF for each rat as compared to the values before thoracotomy (day 0,100\%). We found that the $\mathrm{FS} \%$ and $\mathrm{EF} \%$ in controls decreased significantly and progressively at 2 weeks and 4 weeks after LAD ligation, demonstrating the severe impact of LAD ligation on systolic function in $\mathrm{MI}$ rats. In contrast, the $\mathrm{FS} \%$ and $\mathrm{EF} \%$ in the MSC and TGF- $\beta 2$ group were significantly lower at 2 weeks but after LAD ligation had improved at 4 weeks (Figure 5A, B). At 15 weeks after LAD ligation, the increase in $\mathrm{FS} \%$ and $\mathrm{EF} \%$ was higher in the MSC group than in the TGF- $\beta 2$ group (Figure 5C, D).

\section{Transplantation of human umbilical cord undifferentiated WJ-MSCs or TGF-B2-stimulated WJ-MSCs into MI rat myocardium decreases myocardial fibrosis}

Gross examination of hearts from control rats revealed a large white necrotic area related to fibrosis on the anterior to lateral side of the left ventricle. Heart cross-sections showed significant thinning of the left ventricular wall, with white regions of fibrosis. Masson's Trichrome staining revealed a significant regional distribution of blue fibers on the inside of the left ventricular wall. Gross morphological observations of the MSC and TGF- $\beta 2$ group revealed white areas of fibrosis that were smaller than those of controls. The cross-sections of heart showed no significant thinning of the left ventricular wall in either the MSC or the TGF- $\beta 2$ group. Masson's Trichrome staining revealed only a few blue fibers on the outside of the left ventricular wall (Figure 6).

\section{Survival of the transplanted human umbilical cord WJ-MSCs in rat myocardium}

2 days after transplantation of human umbilical cord undifferentiated WJ-MSCs or TGF- $\beta 2$ stimulated MSCs, we observed fluorescent human cell nuclei in the region where the MSCs had been transplanted, confirming the survival of the transplanted stem cells. However, no clear expression of myocardial specific protein (cardiac Troponin I) co-localized with the fluorescent nuclei (Figure 7A, B). At 15 weeks after transplantation, there were still fluorescent signals indicating human cell nuclei, although the signals were weaker. Similar to the results at 2 days after transplantation, no co-localization of cardiac Troponin I was observed (Figure 7C, D).

Transplantation of human umbilical cord undifferentiated WJ-MSCs or TGF-B2-stimulated WJ-MSCs into MI rat myocardium leads to better survival

The survival rate of rats in the control group was $67 \%$ at 15 weeks. All rats in the other 3 groups survived to 15 weeks (Figure 8).

\section{Discussion}

Previous research has found that injection of embryonic stem cells treated with TGF- $\beta 2$ into myocardial infarction sites improved cardiac function and inhibited fibrosis [32]. Other studies have successfully induced the differentiation of embryonic stem cells into beating cardiac myocytes using TGF- $\beta 2$ treatment [30-32], demonstrating the important role of TGF- $\beta 2$ in cardiac repair and myocardial differentiation. Before starting this study, we observed increased expression of the myocardialspecific proteins C-troponin I and connexin 436 days after MSCs were stimulated with TGF- $\beta 2$, confirming that TGF- $\beta 2$ treatment induced cardiomyocyte differentiation. 


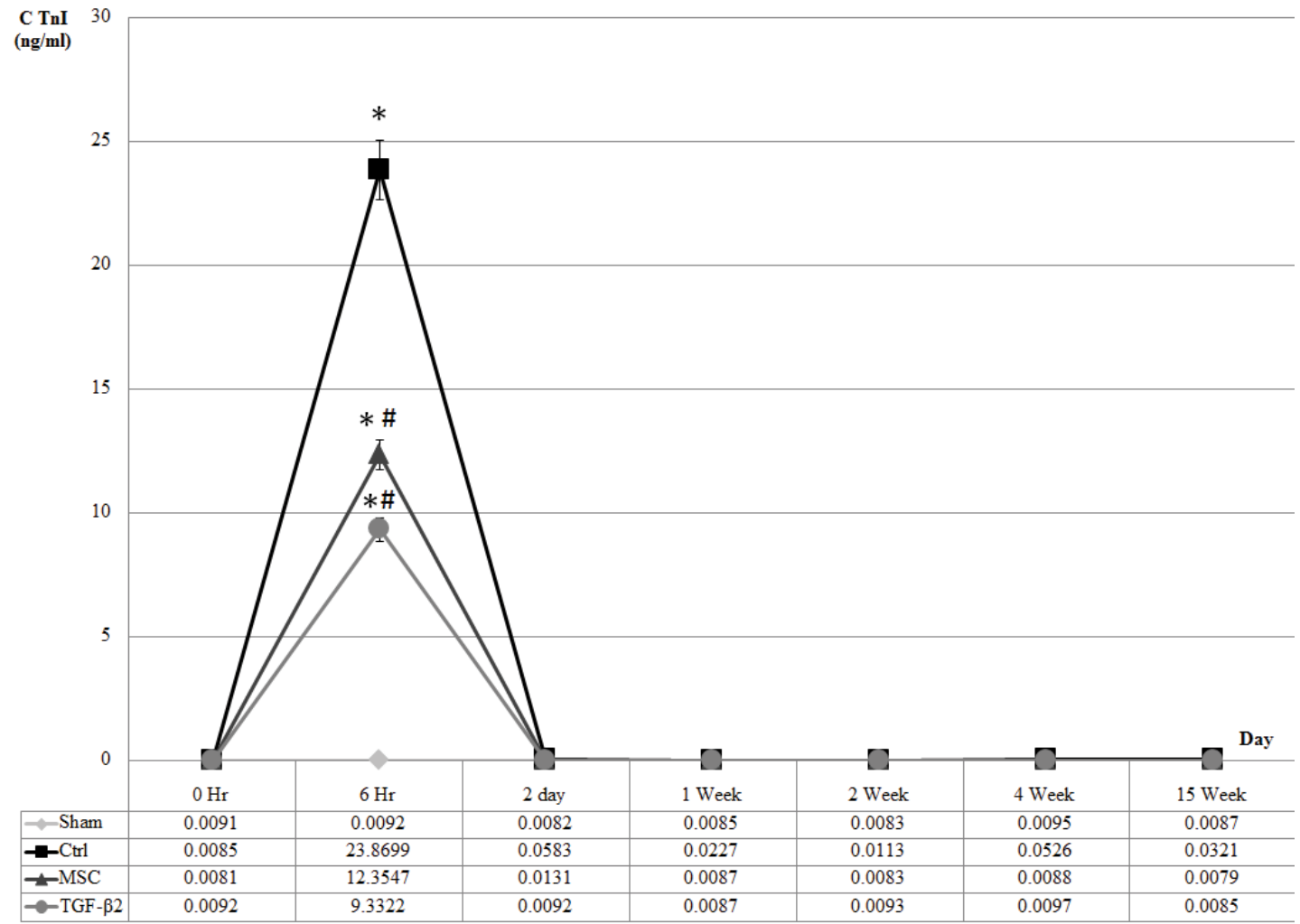

Figure 3 Changes in serum c-Tnl level.

Change in serum cardiac troponin-I (c-Tnl) before (0 Hour), 6 hours, 2 days, 1 week, 2 weeks, 4 weeks, and 15 weeks after LAD ligation in 4 groups. The serum c-Tnl level was significantly lower in both the MSC and TGF- $\beta 2$ groups than in controls 6 hours after LAD ligation. $\left({ }^{*} p<0.05\right.$ vs 0 hour; $\# p<0.05$ vs 6 -hour Ctrl group).

Table 1 Echocardiography M-mode measurements.

\begin{tabular}{|c|c|c|c|c|c|}
\hline & & \multicolumn{4}{|c|}{ M-mode Measurement (cm) } \\
\hline & & Sham & Ctrl & MSC & TGF- $\beta 2$ \\
\hline \multirow{2}{*}{ Day 0} & LVEDD & $0.575 \pm 0.024$ & $0.597 \pm 0.037$ & $0.578 \pm 0.022$ & $0.577 \pm 0.015$ \\
\hline & LVESD & $0.211 \pm 0.014$ & $0.224 \pm 0.022$ & $0.199 \pm 0.010$ & $0.215 \pm 0.021$ \\
\hline \multirow{2}{*}{2 week } & LVEDD & $0.600 \pm 0.018$ & $0.765 \pm 0.059 *$ & $0.682 \pm 0.022^{*}$ & $0.721 \pm 0.064^{* *}$ \\
\hline & LVESD & $0.200 \pm 0.011$ & $0.461 \pm 0.072^{*}$ & $0.336 \pm 0.021^{* * *}$ & $0.395 \pm 0.080^{* * *}$ \\
\hline \multirow{2}{*}{4 week } & LVEDD & $0.611 \pm 0.022$ & $0.764 \pm 0.057^{*}$ & $0.635 \pm 0.023$ & $0.739 \pm 0.072^{* * *}$ \\
\hline & LVESD & $0.202 \pm 0.012$ & $0.479 \pm 0.075^{*}$ & $0.279 \pm 0.012^{* *}$ & $0.353 \pm 0.069^{* *}$ \\
\hline \multirow{2}{*}{15 week } & LVEDD & $0.700 \pm 0.049$ & $0.710 \pm 0.057$ & $0.600 \pm 0.043$ & $0.736 \pm 0.054^{* *}$ \\
\hline & LVESD & $0.241 \pm 0.053$ & $0.402 \pm 0.054$ & $0.245 \pm 0.006 *$ & $0.372 \pm 0.067 * *$ \\
\hline
\end{tabular}

${ }^{*} \mathrm{p}<0.05 ;{ }^{* *} \mathrm{p}<0.01 ;{ }^{* * *} \mathrm{p}<0.001$ vs day 0

In this study, we investigated the therapeutic effects of undifferentiated WJ-MSCs and TGF- $\beta 2$ stimulated WJ-MSCs on left ventricular dysfunction in rats with myocardial infarction. Clinical indicators of myocardial infarction were observed in rats after ligation of the left anterior descending artery, including ECG with ST elevation, increased serum c-Tnl, and decreased FS and EF as measured by echocardiography. We observed the effects of transplantation with undifferentiated WJ-MSCs or TGF- $\beta 2$ stimulated WJ-MSCs into myocardial infarction rats. We found that both FS and EF, useful indicators of left ventricular function, gradually recovered from 2 to 4 weeks after transplantation, whereas those of the control group did not. Echocardiography at 15 weeks after transplantation showed this improvement persisted in both groups injected with undifferentiated WJMSCs and TGF- $\beta 2-$ stimulated WJ-MSCs, in contrast to the control group which exhibited continued deterioration. ECGs were consistent with the echocardiography results. Our data showed not only short-term but also long-term improvement of cardiac function and inhibition of fibrosis in myocardial infarction rats after transplantation of undifferentiated WJ-MSCs or TGF- 32 -stimulated WJ-MSCs. The FS and EF of the MSC group improved significantly as early as 2 weeks after transplantation and continued to 15 weeks. While the FS and EF of the TGF- $\beta 2$ group were similar to those of the control group at 2 weeks, they 


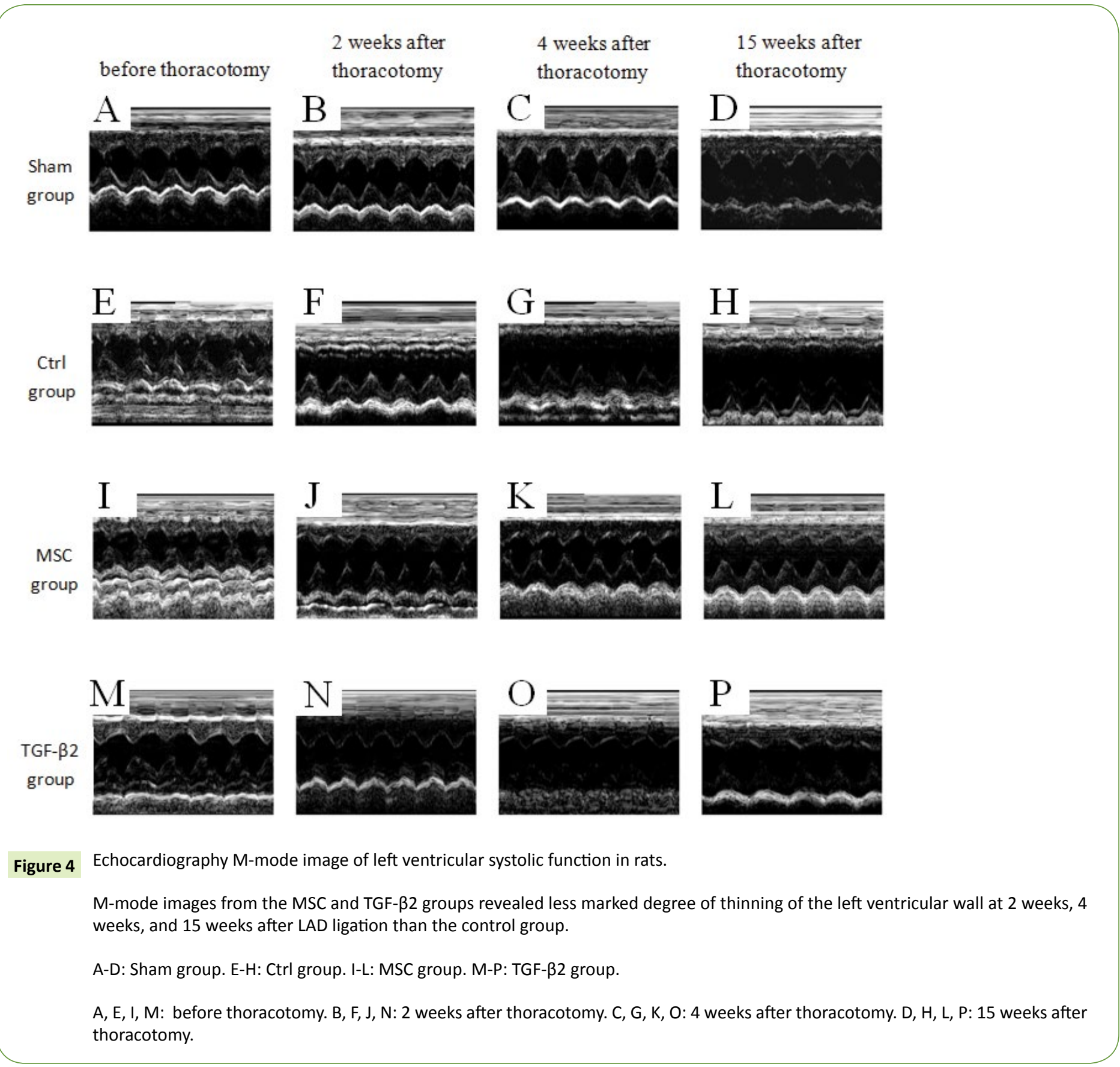

indicated significant recovery at 4 weeks and continued to 15 weeks. The results demonstrate excellent improvement in left ventricular function by the transplantation of undifferentiated WJ-MSCs and TGF- $\beta 2$-stimulated WJ-MSCs, with greatest improvements resulting from treatment with the undifferentiated WJ-MSCs.

Immunohistochemical staining of rat myocardium 2 days and 15 weeks after transplantation revealed the presence of human WJ-MSCs, indicating that the transplanted human WJ-MSCs had successfully grafted into the rat myocardium. However, the number of human WJ-MSCs was small. One possible reason could be that infarcted rat myocardium is a hypoxic environment, lacking nutrients and not conducive for cell growth. Other one study has also reported very low survival rates of bone marrow-derived very small embryonic-like cells in infarcted rat myocardium, even though left ventricular dysfunction and remodeling was attenuated after transplantation of embryonic-like cells [33]. Several studies have pointed out that MSCs were not detectable two week after transplantation [34,35], and the fraction of MSCs was about $1.33 \%$ of the injected cell number. MSCs were hard to detect even 4 weeks after transplantation, and the transplanted cells exhibited no signs of myocardial differentiation [34,35]. However, in the studies of stem cell therapy for myocardial infarction, the survival of stem cells in the infarcted myocardium, true engraftment, and cell function were equally important [36-40].

In general, improved survival rates of stem cells in the infarcted myocardium would lead to greater long-term reparative function and therapeutic effects. Some scientists have focused on improving 
A

The ratio of the variation in FS\% (short term)

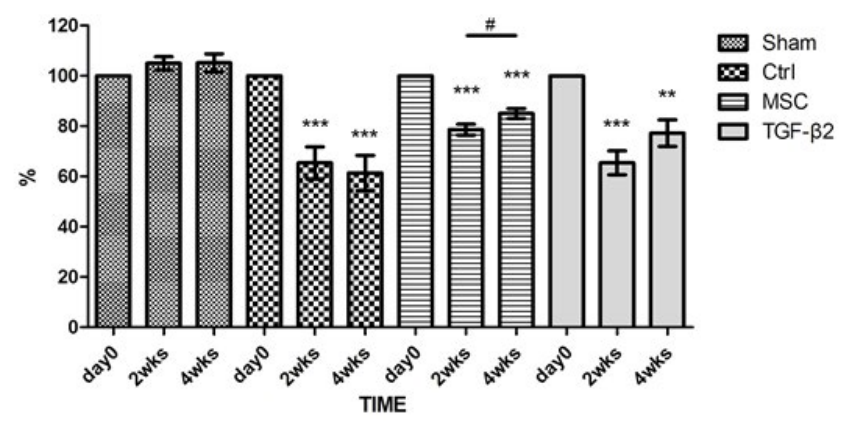

$\mathrm{B}$

The ratio of the variation in $\mathbf{E F} \%$ (short term)

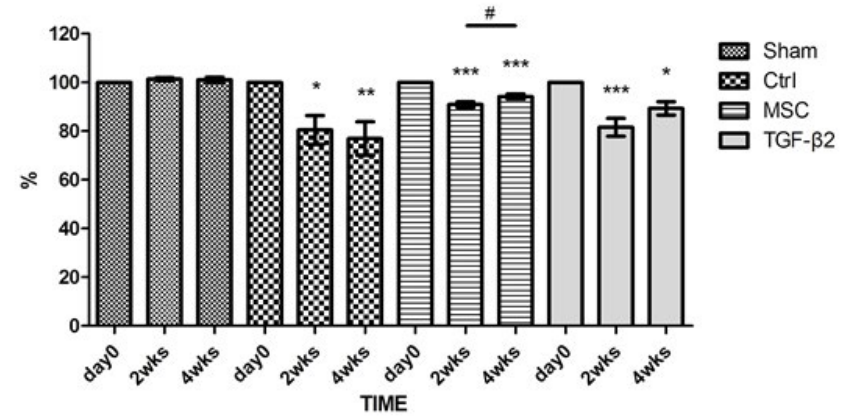

C The ratio of the net variation in FS\% (long term)

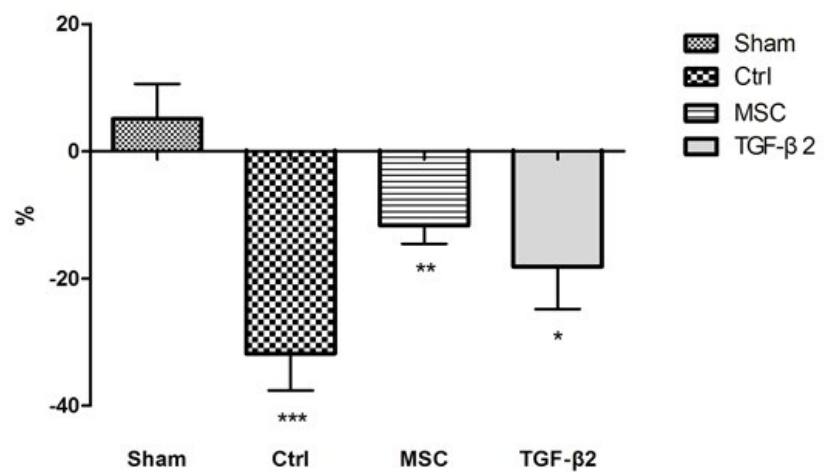

D The ratio of the net variation in EF\% (long term)

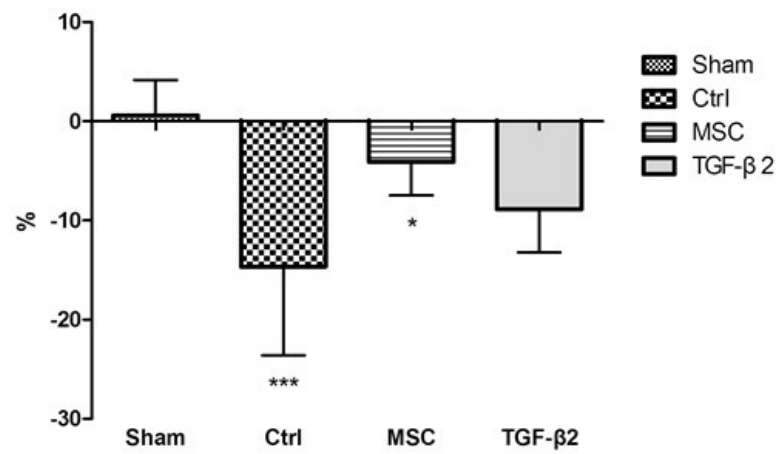

Figure 5 Change in left ventricular systolic function as assessed by echocardiography.

The FS\% and EF\% in the MSC and TGF- $\beta 2$ group were significantly lower at 2 weeks but had improved at 4 weeks (Figure $4 \mathrm{~A}, \mathrm{~B}$ ). At 15 weeks after LAD ligation, the increase in $\mathrm{FS} \%$ and EF\% was higher in the MSC group than in the TGF- $\beta 2$ group. A: Short-term change in FS\% in 4 groups. B: Short-term change in EF\% in 4 groups. Results are relative to preoperative values (day 0), assigned as $100 \%$. ( ${ }^{*} p<0.05$ vs day $0 ;{ }^{* *} p<0.01$ vs day $0 ;{ }^{* *} p<0.001$ vs day $0 ; \# p<0.05$ vs 2 weeks.) C: Long-term net change in $\mathrm{FS} \%$ in 4 groups. D: Long-term net change in EF\% in 4 groups. ( ${ }^{*} p<0.05$ vs day $0 ;{ }^{*} p<0.01$ vs day $0 ; * * * p<0.001$ vs day 0 ).

survival rates of transplanted cells through pretreatment with melatonin $[41,42]$. Others have used intramyocardial peptide nanofiber injection to improve survival and retention rates in damaged myocardium $[43,44]$. In our study, we transplanted stem cells directly into the myocardium, allowing them to act directly on the damaged myocardiocytes without having to travel through the blood, a journey that results in the loss of injected cells. This direct transplantation method may account for the survival of human cells not only 2 days after but also 15 weeks after transplantation, although the number of cells was small.

Stem cell transplantation is regarded as a promising approach in the field of regenerative medicine for heart disease. As a result, many types of stem cells from different sources have been used in myocardial infarction treatment research. For example, CD133+ cells isolated from human umbilical cord blood possess hematopoietic and angiogenic capabilities. In one study, observation one month after transplantation into athymic infarcted rat myocardium revealed that the presence of $\mathrm{CD} 133+$ cells led to thicker scar tissue formation, achieving a protective effect. Echocardiography also revealed greater improvement in left ventricular function, exerting positive effects extending to the spleen and liver [45]. A 2007 study demonstrated that bonemarrow-derived MSCs from ischemic heart disease patients transplanted into infarcted myocardium of NOD mice exhibited signs of vascular endothelial cell differentiation and improved left ventricular function [46]. Researchers attempting stem cell repair of myocardial infarction in animal models speculate that stem cells may differentiate into myocardial or vascular endothelial cells to compensate for sites of damage in the infarcted myocardium and to provide the required angiogenesis [34-36,38-40,47]. In addition, stem cells secrete cytokines such as vascular endothelial growth factor, stromal cell-derived factor-1, and interleukin-10, which promotes angiogenesis, inhibits inflammation, decreases fibrosis, and prevents apoptosis [48-51].

In this study, both undifferentiated and TGF- $\beta 2$-treated human umbilical cord Wharton's jelly MSCs had therapeutic effects on 


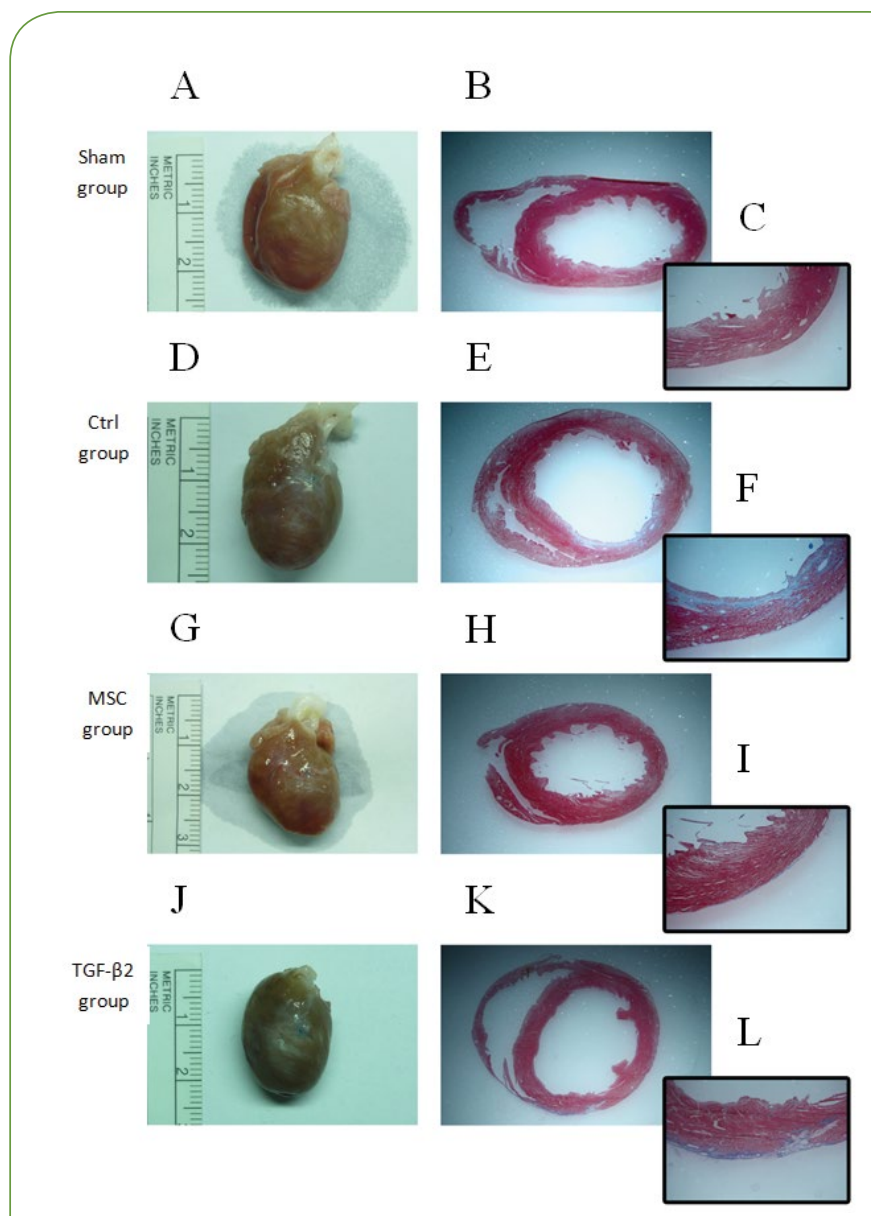

Figure 6

Gross morphology and myocardial fibrosis imaging of rat heart.

The gross morphology of heart and Masson's Trichrome-stained heart tissue cross-sections 15 weeks after thoracotomy are shown. Red regions indicate normal myocardium; blue regions indicate fibrosis. Decreased myocardial fibrosis was found in MSC group and TGF- $\beta 2$ group.

A-C: sham group. D-F: Ctrl group. G-I: MSC group. J-L: TGF- $\beta 2$ group.

$A, D, G, J$ : gross anatomy of heart. B, E, H, K: crosssections of heart tissue (40x). C, F, I, L: cross-sections of heart tissue $(400 \times)$.

myocardial infarction by reducing fibrosis and thinning of the left ventricular wall to improve left ventricular function. In addition, our study found human cells in the transplanted WJ-MSCs in rat myocardium but no evidence of co-localized expression of cardiac-specific proteins. Thus, we hypothesize that the MSCs could achieve their therapeutic effects without differentiating into new cardiac cells to replace cells lost due to apoptosis. In other studies, researchers have also speculated that stem cells do not directly repair the damaged myocardium, but rather promote myocardial repair through paracrine mechanisms. The secretion of factors into the circulatory system either stimulates autologous stem cells to differentiate into cardiac cells to repair damage or induces angiogenesis, raising levels of oxygen and nutrients in the myocardium [52].

\section{Conclusion}

In this study, transplantation of both undifferentiated WJ-MSCs and TGF-B2-stimulated WJ-MSCs improved left ventricular function and survival rates and decreased fibrosis in myocardial infarction rats. These effects were particularly pronounced with undifferentiated WJ-MSCs. These results indicate a potential stem cell source for myocardial infarct therapy. Elucidation of the specific mechanisms underlying these effects requires further investigation.

\section{Authors Contributions}

All authors participated in various aspects of the study analysis, interpretation of the data, and the development of the report. The final version was seen and approved by all authors.

\section{Conflicts of interest}

The authors declare that all of the authors have no competing interests.

\section{Grant support for the research reported}

This research was partly supported by research grants from Taipei Veterans General Hospital (V101C-181, V101E1-004) to TH Chen; the National Science Council, Taiwan (NSC102-2314-B-010-041MY3) to TH Chen; the Ministry of Science and Technology, Taiwan (NSC 97-2320-B-010-019-MY3 MOST 101-2320-B-010-040-MY3) to HS Wang; the Ministry of Education, Taiwan, Aim for the Top University Plan to HS Wang and TH Chen; and Cheng Hsin General Hospital (102F218C22, 103F003C12) to TH Chen and CH Su. We declare that the sponsors of the research and the authors have no conflicts of interest to report. The funding source had no role in the study design, data collection, data interpretation, data analysis, or writing of the report. The corresponding authors have full access to all data from the study, as well as responsibility for the final decision to submit the manuscript for publication.

\section{Acknowledgments}

This research was partly supported by research grants from Taipei Veterans General Hospital (V101C-181, V101E1-004) to T-H Chen; the National Science Council, Taiwan (NSC102-2314-B-010-041MY3) to T-H Chen; the Ministry of Science and Technology, Taiwan (NSC 97-2320-B-010-019-MY3 MOST 101-2320-B-010-040-MY3) to H-S Wang; the Ministry of Education, Taiwan, Aim for the Top University Plan to H-S Wang and T-H Chen; and Cheng Hsin General Hospital (102F218C22, 103F003C12) to T-H Chen and Su. 
A
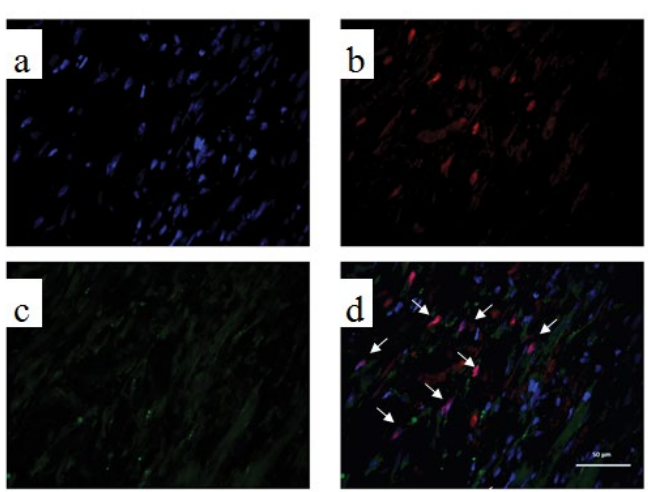

B
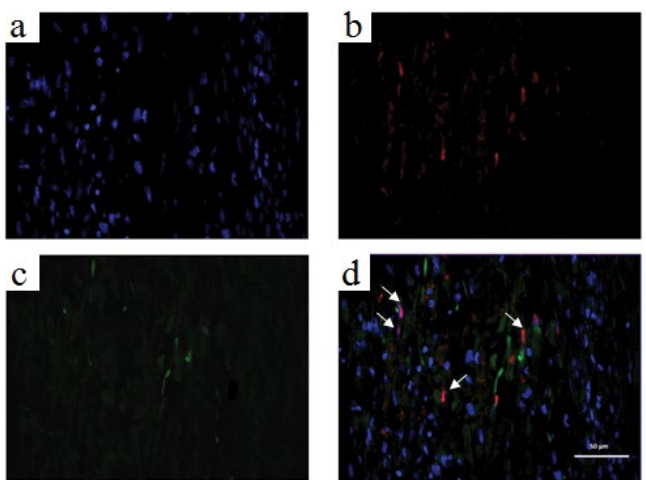

C
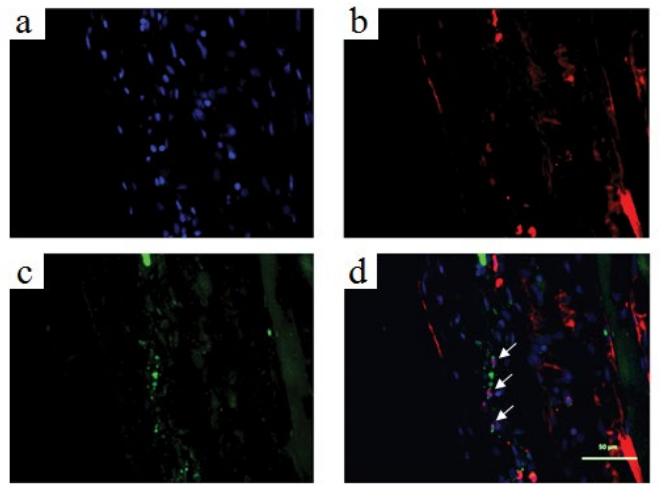

$\mathrm{D}$
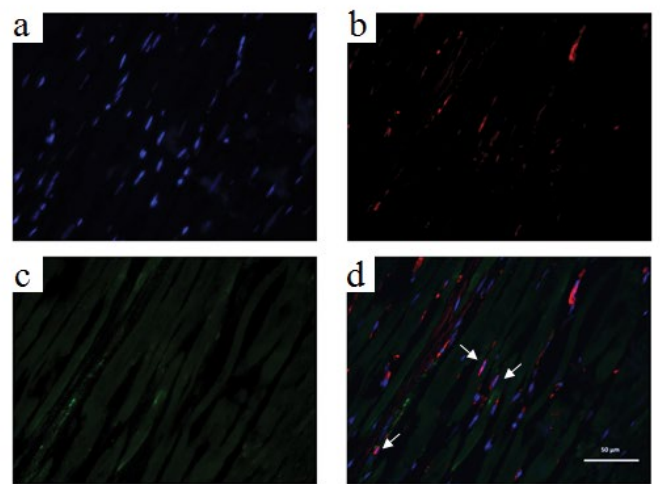

Figure 7 Detection of c-Tnl expression and human nuclei through immunofluorescence staining of rat cardiac tissue sections.

Fluorescent human cell nuclei were observed 2 days as well as 15 weeks after transplantation of human umbilical cord undifferentiated WJ-MSCs or TGF- $\beta 2$ stimulated MSCs, confirming the survival of the transplanted stem cells.

$A: 2$ days after $L A D$ ligation and transplantation of undifferentiated MSCS

B: 2 days after LAD ligation and transplantation of TGF- $\beta 2$-stimulated MSCS

C: 15 weeks after LAD ligation and transplantation of undifferentiated MSCs

D: 15 weeks after LAD ligation and transplantation of TGF- $\beta 2-$ stimulated MSCs

a: blue fluorescence, Hoechst 33258 staining for cell nuclei

b: red fluorescence, staining for human nuclei

c: green fluorescence, staining for c-Tnl

$\mathrm{d}$ : merged image of $a, b$, and c; arrows indicate transplanted human cells.

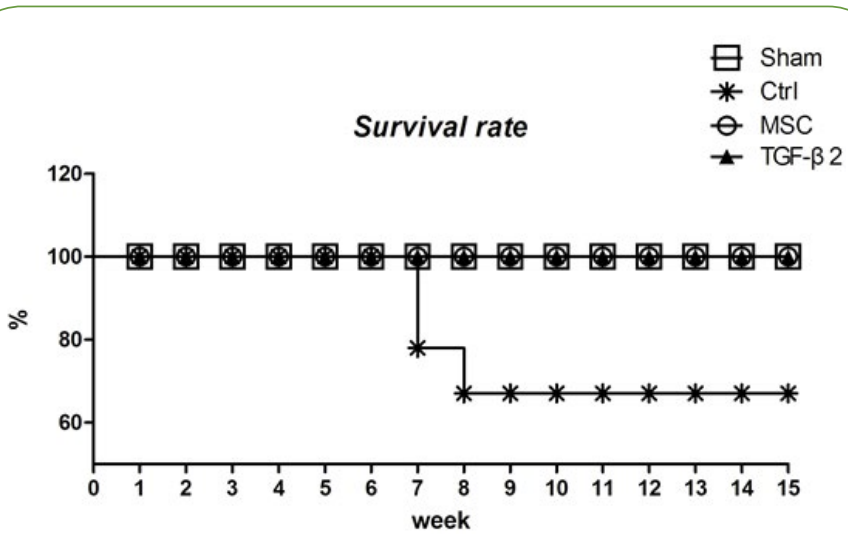

Figure 8 Survival rates of rats in MSC group and TGF- $\beta 2$ group were higher than control group.c. 


\section{References}

1 Takahashi M (2010) Role of the SDF-1/CXCR4 system in myocardial infarction. Circ J 74: 418-423.

2 Tang XL, Rokosh G, Sanganalmath SK, Yuan F, Sato H, et al. (2010) Intracoronary Administration of Cardiac Progenitor Cells Alleviates Left Ventricular Dysfunction in Rats With a 30-Day-Old Infarction. Circulation 121: 293-305.

3 Tang XL, Rokosh DG, Guo Y, Bolli R (2010) Cardiac Progenitor Cells and Bone Marrow-Derived Very Small Embryonic-Like Stem Cells for Cardiac Repair After Myocardial Infarction. Circ J 74: 390-404.

4 Nir S (2003) Human embryonic stem cells for cardiovascular repair. Cardiovascular Research 58: 313-323.

5 Sabbah HN, Sharov VG (1998) Apoptosis in heart failure. Progress in Cardiovascular Diseases 40: 549-562.

6 Prockop DJ (1997) Marrow stromal cells as stem cells for nonhematopoietic tissues. Science 276: 71-74.

7 Docheva D, Popov C, Mutschler W, Schieker M (2007) Human mesenchymal stem cells in contact with their environment: surface characteristics and the integrin system. J Cell Mol Med 11: 21-38.

8 Lee KD, Kuo TKC, Whang-Peng J, Chung YF, Lin CT, et al. (2004) In vitro hepatic differentiation of human mesenchymal stem cells. Hepatology 40: 1275-1284.

9 Lee OKS, Ko YC, Kuo TK, Chou SH, Li HJ, et al. (2004) Fluvastatin and lovastatin but not pravastatin induce neuroglial differentiation in human mesenchymal stem cells. J Cell Biochem 93: 917-928.

10 Pittenger MF, Mackay AM, Beck SC, Jaiswal RK, Douglas R, et al. (1999) Multilineage potential of adult human mesenchymal stem cells. Science 284: 143-147.

11 Wang HS, Hung SC, Peng ST, Huang CC, Wei HM, et al. (2004) Mesenchymal stem cells in the Wharton's jelly of the human umbilical cord. Stem Cells 22: 1330-1337.

12 Troyer DL, Weiss ML (2008) Wharton's jelly-derived cells are a primitive stromal cell population. Stem Cells 26: 591-599.

13 Zhang YN, Lie PC, Wei X (2009) Differentiation of mesenchymal stromal cells derived from umbilical cord Wharton's jelly into hepatocyte-like cells. Cytotherapy 11: 548-558.

14 Huang J, Zhang Z, Guo J, Ni A, Deb A, et al. (2010) Genetic Modification of Mesenchymal Stem Cells Overexpressing CCR1 Increases Cell Viability, Migration, Engraftment, and Capillary Density in the Injured Myocardium. Circ Res 106: 1753-1762.

15 Can A, Karahuseyinoglu S (2007) Concise review: human umbilical cord stroma with regard to the source of fetus-derived stem cells. Stem Cells 25: 2886-2895.

16 Weiss ML, Anderson C, Medicetty S, Seshareddy KB, Weiss RJ, et al. (2008) Immune Properties of Human Umbilical Cord Wharton's JellyDerived Cells. Stem Cells 26: 2865-2874.

17 Barry FP, Murphy JM (2004) Mesenchymal stem cells: clinical applications and biological characterization. Int J Biochem Cell Biol 36: $568-584$

18 Grinnemo KH, Månsson A, Dellgren G, Klingberg D, Wardell E, et al. (2004) Xenoreactivity and engraftment of human mesenchymal stem cells transplanted into infarcted rat myocardium. J Thorac Cardiovasc Surg 127: 1293-1300.
19 Orlic D, Kajstura J, Chimenti S, Bodine DM, Leri A, et al. (2003) Bone marrow stem cells regenerate infarcted myocardium. Pediatric Transplantation 7: 86-88.

20 Schuh A, Liehn EA, Sasse A, Hristov M, Sobota R, et al. (2008) Transplantation of endothelial progenitor cells improves neovascularization and left ventricular function after myocardial infarction in a rat model. Basic Res Cardiol 103: 69-77.

21 Kucia M, Reca R, Campbell FR, Zuba-Surma E, Majka M, et al. (2006) A population of very small embryonic-like (VSEL) CXCR4(+)SSEA-1(+)Oct4+ stem cells identified in adult bone marrow. Leukemia 20: 857-869.

22 Min J-Y, Sullivan MF, Yang Y, Zhang J-P, Converso KL, et al. (2002) Significant improvement of heart function by cotransplantation of human mesenchymal stem cells and fetal cardiomyocytes in postinfarcted pigs. Ann Thorac Surg 74: 1568-1575.

23 Bartram U, Molin DGM, Wisse LJ, Mohamad A, Sanford LP, et al. (2001) Double-Outlet Right Ventricle and Overriding Tricuspid Valve Reflect Disturbances of Looping, Myocardialization, Endocardial Cushion Differentiation, and Apoptosis in TGF- 2-Knockout Mice. Circulation 103: 2745-2752.

24 Sinha S, Hoofnagle MH, Kingston PA, McCanna ME, Owens GK (2004) Transforming growth factor-beta1 signaling contributes to development of smooth muscle cells from embryonic stem cells. Am J Physiol Cell Physiol 287: C1560-1568.

25 Lidral AC, Romitti PA, Basart AM, Doetschman T, Leysens NJ, et al. (1998) Association of MSX1 and TGFB3 with Nonsyndromic Clefting in Humans. Am J Hum Genet 63: 557-568.

26 Christ M, McCartney-Francis NL, Kulkarni AB, Ward JM, Mizel DE, et al. (1994) Immune dysregulation in TGF-beta 1-deficient mice. J Immunol 153: 1936-1946.

27 Dickson MC, Martin JS, Cousins FM, Kulkarni AB, Karlsson S, et al. (1995) Defective haematopoiesis and vasculogenesis in transforming growth factor-beta 1 knock out mice. Development 121: 1845-1854.

28 Sanford LP, Ormsby I, Gittenberger-de Groot AC, Sariola H, et al. (1997) TGFbeta2 knockout mice have multiple developmental defects that are non-overlapping with other TGFbeta knockout phenotypes. Development 124: 2659-2670.

29 Azhar M, Schultz JEJ, Grupp I, Dorn GW, Meneton P, et al. (2003) Transforming growth factor beta in cardiovascular development and function. Cytokine \& Growth Factor Rev 14: 391-407.

30 Kumar Singla D, Sun B (2006) Corrigendum to Transforming growth factor-2 enhances differentiation of cardiac myocytes from embryonic stem cells [Biochem. Biophys. Res. Commun. 332 (2005) 135141]. Biochemical and Biophysical Research Communications 344: 1361.

31 Kumar D, Sun B (2005) Transforming growth factor- $\hat{I}^{2} 2$ enhances differentiation of cardiac myocytes from embryonic stem cells. Biochemical and Biophysical Research Communications 332: 135-141.

32 Singla DK, Singla RD, Lamm S, Glass C (2011) TGF- 2 treatment enhances cytoprotective factors released from embryonic stem cells and inhibits apoptosis in infarcted myocardium. Am J Physiol Heart Circ Physiol 300: H1442-H1450.

33 Wu JH, Wang HJ, Tan YZ, Li ZH (2012) Characterization of rat very small embryonic-like stem cells and cardiac repair after cell transplantation for myocardial infarction. Stem Cells Dev 21: 1367-1379.

34 Ishikane S, Hosoda H, Yamahara K, Akitake Y, Kyoungsook J, et al. (2013) Allogeneic transplantation of fetal membrane-derived mesenchymal 
stem cell sheets increases neovascularization and improves cardiac function after myocardial infarction in rats. Transplantation 96: 697706.

35 Mazo M, Gavira JJ, Abizanda G, Moreno C, Ecay M, et al. (2010) Transplantation of Mesenchymal Stem Cells Exerts a Greater LongTerm Effect Than Bone Marrow Mononuclear Cells in a Chronic Myocardial Infarction Model in Rat. Cell Transplant 19: 313-328.

36 Zhang W, Liu XC, Yang L, Zhu DL, Zhang YD, et al. (2013) Wharton's jelly-derived mesenchymal stem cells promote myocardial regeneration and cardiac repair after miniswine acute myocardial infarction. Coron Artery Dis 24: 549-558.

37 Zakharova L, Nural-Guvener H, Feehery L, Popovic-Sljukic S, Gaballa MA (2015) Transplantation of Epigenetically Modified Adult Cardiac c-Kit+ Cells Retards Remodeling and Improves Cardiac Function in Ischemic Heart Failure Model. Stem Cells Transl Med 4: 1086-1096.

38 Hao L, Hao J, Fang W, Han C, Zhang K, et al. (2015) Dual isotope simultaneous imaging to evaluate the effects of intracoronary bone marrow-derived mesenchymal stem cells on perfusion and metabolism in canines with acute myocardial infarction. Biomed Rep 3: $447-452$.

39 Tang XL, Rokosh G, Sanganalmath SK, Tokita Y, Keith MC, et al. (2015) Effects of Intracoronary Infusion of Escalating Doses of Cardiac Stem Cells in Rats With Acute Myocardial Infarction. Circ Heart Fail 8: 757765.

40 Nascimento DS, Mosqueira D, Sousa LM, Teixeira M, Filipe M, et al. (2014) Human umbilical cord tissue-derived mesenchymal stromal cells attenuate remodeling after myocardial infarction by proangiogenic, antiapoptotic, and endogenous cell-activation mechanisms. Stem Cell Res Ther 5: 5.

41 Mias C, Trouche E, Seguelas MH, Calcagno F, Dignat-George F, et al. (2008) Ex Vivo Pretreatment with Melatonin Improves Survival, Proangiogenic/Mitogenic Activity, and Efficiency of Mesenchymal Stem Cells Injected into Ischemic Kidney. Stem Cells. 26: 1749-1757.

42 Han D, Huang W, Li X, Gao L, Su T, et al. Melatonin facilitates AdiposeDerived Mesenchymal Stem Cells to repair the murine infarcted heart via the SIRT1 signaling pathway. J Pineal Res

43 Lin YD, Yeh ML, Yang YJ, Tsai DC, Chu TY, et al. (2010) Intramyocardial
Peptide Nanofiber Injection Improves Postinfarction Ventricular Remodeling and Efficacy of Bone Marrow Cell Therapy in Pigs. Circulation 2010;122S132-S141.

44 Nelson DM, Ma Z, Fujimoto KL, Hashizume R, Wagner WR (2011) Intra-myocardial biomaterial injection therapy in the treatment of heart failure: Materials, outcomes and challenges. Acta Biomater 7: 1-15.

45 Leor J, Guetta E, Feinberg MS, Galski H, Bar I, et al. (2006) Human umbilical cord blood-derived CD133+ cells enhance function and repair of the infarcted myocardium. Stem Cells 24: 772-780.

46 Grauss RW, Winter EM, van Tuyn J, Pijnappels DA, Steijn RV, et al. (2007) Mesenchymal stem cells from ischemic heart disease patients improve left ventricular function after acute myocardial infarction. Am J Physiol Heart Circ Physiol 293: H2438-H447

47 Karantalis V, Balkan W, Schulman IH, Hatzistergos KE, Hare JM (2012) Cell-based therapy for prevention and reversal of myocardial remodeling. Am J Physiol Heart Circ Physiol 303: H256-270.

48 Gu M, Nguyen PK, Lee AS, Xu D, Hu S, et al. (2012) Microfluidic Single Cell Analysis Show Porcine Induced Pluripotent Stem CellDerived Endothelial Cells Improve Myocardial Function by Paracrine Activation. Circ Res 111: 882-893.

49 Park HW, Moon HE, Kim HS, Paek SL, Kim Y, et al. (2015) Human umbilical cord blood-derived mesenchymal stem cells improve functional recovery through thrombospondin1, pantraxin3, and vascular endothelial growth factor in the ischemic rat brain. J Neurosci Res 93: 1814-1825.

50 Zhang LX, Shen LL, Ge SH, Wang LM, Yu XJ, et al. (2015) Systemic BMSC homing in the regeneration of pulp-like tissue and the enhancing effect of stromal cell-derived factor-1 on BMSC homing. Int J Clin Exp Pathol 8: 10261-10271.

51 Pluchino S, Cossetti C (2013) How stem cells speak with host immune cells in inflammatory brain diseases. Glia 61: 1379-1401.

52 Agbulut O, Vandervelde S, Al Attar N, Larghero J, Ghostine S, et al. (2004) Comparison of human skeletal myoblasts and bone marrowderived CD133+ progenitors for the repair of infarcted myocardium. J Am Coll Cardiol 44: 458-63. 